\title{
HACIA UN MAPA DE LA AUDIENCIACIÓN: CONFORMACIÓN DE NUEVAS AUDIENCIAS EN LA HISTORIA DE LA MEDIATIZACIÓN
}

\author{
Leonel Yáñez Uribe ${ }^{1}$
}

\section{Resumen/Abstract}

La escena hipermediática actual, donde los medios modernos de comunicación convergen a la red de redes y su digitalización interpela nuevos vínculos y contratos con sus audiencias. Allí, en esas transformaciones, es posible levantar una caracterización del sujeto epocal de la comunicación social, al que le hemos llamado "el comunicante". Bajo estas consideraciones que vienen a renovar el campo de investigación de la mediatización cabe una pregunta básica: ¿los procesos de producción, circulación y reconocimiento de sentido, en la actualidad, hacen posible construir o formar nuevas audiencias?

Palabras Claves: inter sistema, audienciación, reconocimiento, objeto temporal, flujo, selección, montaje

TOWARD A HEARING MAP: CONFORMATION OF NEW AUDIENCES IN THE HISTORY OF MEDIATIZATION

The current hypermedia scene, where modern media converge to the network of networks and its digitization challenges new links and contracts with its audiences. In these transformations, it is possible to raise a characterization of the epochal subject of social communication, which we have

${ }^{1}$ Chileno. E-mail: leoyanezuribe@gmail.com 
called "the communicant." Under the considerations that come to renew the field of investigation of the mediation a basic question it arises: do the processes of production, circulation and recognition of sense make possible, at present, to construct or to form new audiences?

Keywords: inter system, audience, recognition; temporal object; flow, selection, assembly

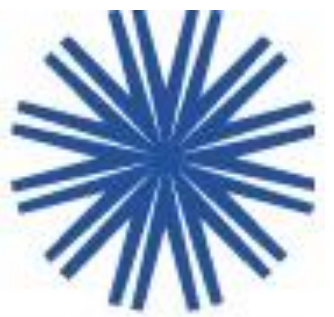

\section{Introducción}

Los estudios de audiencias han objetivado al sujeto y han ubicado a la técnica como lugar de un afuera. Desde allí, se han sucedido los procedimientos orientados al montaje de la realidad, especialmente a través de la televisión y los telediarios, su construcción social y mediática. ¿Qué está pasando ahora en que los medios convergen hacia Internet? ¿Cuáles son las rupturas y continuidades? al respecto ${ }^{2}$

Bajo estas líneas, el concepto central que surge es el de "reconocimiento", comprendido éste como contrato/vínculo en la interrelación de los medios con la sociedad, es decir, sus individuos y sus procesos de individuación (Simondon, 2009).

\footnotetext{
${ }^{2}$ Este artículo está basado en el capítulo III de la tesis para optar a grado de Doctor en Cultura y Educación, "De las audiencias a la audienciación: constribuciones para la actualización de un fenómeno constitutivo de la vida social contemporánea", en proceso de revisión y defensa, por parte del autor.
} 
Revista de la Academia/ISSN 0719-6318

Cabe también otra pregunta: ¿Estos vínculos han variado con el advenimiento de la digitalización de los medios?

La respuesta a estas interrogantes, deberían permitir representar un mapa (nuevo) de los sistemas de audienciación, considerando los binomios nuevos/viejos medios de comunicación.

De este modo podemos informar acerca del estado actual del problema, por lo que estaríamos en condiciones de levantar un aporte a una teoría contemporánea de las audiencias sobre la configuración de una circulación de sentido que opera en tanto flujos y movimientos, instalando unas dinámicas que proponen lugares intermedios donde se configura y reconfigura la producción de sentido: el montaje.

A la finitud retencional, la estrategia ortética, ha llevado a la cultura a la creación de un "qué" que permite dar estabilidad a la realidad efímera de todo recuerdo precario, que no es sino, un otro momento en la historia de la mediatización, ahora hipermediatizado. Restaría que esa órtesis, fuera trasplantada hacia la biología humana, provocando con ello un doble movimiento: exteriorización/interiorización de las técnicas en relación con las personas. Pero como sabemos, eso aún huele a ficción, por lo que vale retroceder un poco, y la posibilidad y condición de pensar la comunicación social, superando su episteme fundacional funcionalista. 
Los conceptos claves que animan este artículo aparecen enunciados como:

\section{La comunicación como proceso}

Qué entendemos por procesos de comunicación. Proponemos caracterizarlo desde nuestro enfoque inter sistemas (sistema social/sistemas psíquicos), necesariamente distinguible de aquellos que han gravitado fuertemente en la teoría de la comunicación, particularmente los sistemas unidireccionales, los sistemas basados en propósitos (Berlo), el sistema interacciónal (Bateson), y el sistema sociosemiótico (Verón), del cual nos declaramos fuertemente emparentados, por cierto.

$\mathrm{El}$ argumento que fundamenta la propuesta de un enfoque inter sistema, para entender los procesos de la comunicación, tiene relación con que ésta corresponde a un acto biopsicosocial. Los modelos funcionalistas y otros, han reproducido permanentemente, un estado unidireccional donde el emisor se relaciona hegemónicamente con el conjunto de los eventos y elementos que integran a los procesos comunicativos. Pero si interpretamos a la comunicación como parte de la cultura, ésta sin comunicación, no sería posible. En la relación ser humano/ecosistema se instala la facultad fundamental del homo sapiens, que es la de comunicar (se), centralidad que adquiere mayor pertinencia en este tipo sociedades. Entonces 
Revista de la Academia/ISSN 0719-6318

abrámonos a otra pregunta: ¿Cómo la comunicación se ha ido conociendo científicamente?

La mayor de las veces es explicada en su relación a un macro sistema, es decir, unos procesos que configuran a la comunicación como un sistema; por ello, a fin de diferenciar algunos enfoques al respecto, sintetizaremos cuatro (4) universos paradigmáticos de sistemas, desde la comunicología, a saber:

1.- El sistema Berloniano, forma y proceso donde la comunicación es vista como propósito, con anclaje en los sistemas unidireccionales, es decir, se acentúa el lugar del emisor.

2.- El sistema luhmanniano, la comunicación como sistema social que distingue subsistemas, y entre éstos, específicamente el "subsistema mediático".

3.- El sistema batesoniano, la interacción humana y los contextos relacionales, donde la comunicación constituiría realidad por lo que no es posible pensar la "no comunicación".

4.- El sistema Veroniano, la sociosemiosis que entrega como perspectiva la interrelación del sistema social y el sistema psíquico, como dispositivo de producción de sentido.

David Berlo en su texto "Proceso de la Comunicación" (Berlo, 1984) estima que la acción comunicativa requiere propósitos 
claros a nivel del emisor, que, a través de las competencias, claridad de propósitos, como de los contextos en que se sitúa, configuran el mapa de su accionar. Por ello es que en la obra "El proceso de la comunicación: introducción a la teoría y la práctica", identifica y analiza los diversos factores implicados en el proceso, bajo la hipótesis de que su comprensión ayudará al ser humano a resolver sus problemas vitales. De este modo, se propone el autor superar el ramplón enfoque conductista de la comunicación humana, poniendo énfasis en lo que sucede en tanto proceso y qué sentido lo orienta. En esa medida, el ser humano podrá valerse de sus competencias comunicativas y así ser un agente efectivo de cambio y pueda alterar positivamente "la relación original que existe entre su organismo y el medio que lo circunda". (López, Simonetti, y Parada, 1991: 93) Da énfasis a la cuestión del mensaje, su manejo y dominio en tanto contenido, puesto que allí se encuentra el propósito último de la comunicación: es decir, estamos hablando de la claridad de propósito, como fuente de toda emisión. Porque los fracasos, en el influir a los otros, pueden deberse al desconocimiento de esos fines, o al uso de hábitos rutinarios de comunicarse, lo que derivaría como consecuencia, a una interpretación errónea de la respuesta que la persona quiere provocar. Por lo que la intencionalidad y los propósitos de toda comunicación, vienen a ser los aspectos sensibles de la misma. Es que con Berlo, aún estamos a medio camino de pensar la comunicación, como un fenómeno de mayor complejitud. Es decir, si somos conscientes de las 
partes de ese proceso, es posible ganar en eficacia. Por lo que se deduce un sentido instrumental de la facultad propiamente tal.

A diferencia de Berlo, Niklas Luhmann complejiza el fenómeno de la comunicación a nivel de "sistema": "el sistema social reproduce la comunicación tal y como los sistemas vivos reproducen la vida, los sistemas psíquicos reproducen la conciencia”. (Urteaga, 2010: 303) Este sistema social constituye ciertas especificidades posible de llamarle "subsistemas opacos", que serían los elementos, esferas si se quiere, que autónomamente adquiere presencia en las sociedades más complejas, como el subsistema político, el jurídico, el económico; así también siguiendo a Luhmann, la presencia ya consolidada por más de 500 años de un subsistema mediático, el que tendría una preponderancia importante en este tipo de sociedades. Estos otros subsistemas, vienen a plantearse como "sistemas observadores", donde es fundamental la perspectiva donde se "rompe con el presupuesto de que hay un actor o una acción detrás de la comunicación social”, pues ésta perspectiva da un paso más, al considerar una desidentización en la idea de sistema, y más bien considerar una "diferencia" entre el sistema y el entorno: "El sistema no existe en sí mismo sino que sólo existe y se mantiene gracias a su distinción con el entorno". (Ibídem) Su arquitectura considera tres grandes tipos de sistemas: 
“...el sistema vivo, el sistema psíquico y el sistema social. El primero se reproduce gracias a la vida, el segundo lo hace vía la conciencia y el tercero se perpetúa a través de la comunicación (...) en la medida en que las sociedades modernas se caracterizan por una diferenciación de sus sistemas en subsistemas (...) El sistema está cerrado por sus propias operaciones y su entorno solo le afecta en la medida en que lo ha determinado". (Ibídem:304)

Sobre una teoría más allá de la disciplina sociológica, Luhmann concurre a la neurociencia, y desde allí puede explicar el fenómeno de nuestro aparato cognitivo como un sistema operativo cerrado, sistema nervioso que sería incapaz de "incidir sobre su propio entorno". No controlaría la causalidad que genera en el medio lo que "Concierne tanto al sistema psíquico, incapaz de alcanzar otro sistema, como al sistema social, incapaz de controlar los efectos que genera en su entorno natural, como a la interrelación de los subsistemas sociales entre sî", (Ibídem) y por ello, el conocimiento no puede verse como un espejo de aquello dado (la realidad) sino y por el contrario, "sin apenas entrar en contacto" con el entorno, produce sus propios acercamientos a esa realidad. Habría un sistema, que permite las operaciones autoorganizadas -imaginamos-, con cierta base en los postulados de Varela y Maturana, así como de las primeras teorías cibernéticas. De allí que, Luhmann diferencia ciertos procesos comunicativos según la complejidad de las sociedades, dando cuenta a los menos de aquellos procesos basados en la "descendencia" o la "residencia", donde se 
realizan las interrelaciones "cara a cara"; o aquellas de orden más civilizatorias entre una cultura y otra del tipo “civilizado/no civilizado" hasta la diferenciación

"por estratos" donde existen unas hegemonías según la superioridad de las castas. Así, “el sistema social está formado por la comunicación, la evolución hacia la diferenciación depende de la producción de semánticas autónomas". (Ibídem: 308) En ese conocer sistémico, Verón encuentra similitud con los postulados de Pierce (la triada pierciana), por eso lo convoca y lo propone como un lugar de sus argumentaciones; las concordancias con Luhmann estarían siendo reconocidas en las definiciones que vemos en el "esquema ternario", particularmente en estas claves fundamentales:

"Un sistema social no es otra cosa que un sistema que se reproduce autopoiéticamente a través de actos de comunicación. Luhmann define un acto de comunicación como la síntesis de tres selecciones: información, enunciación [utterance], y comprensión [understanding], que incluye la no comprensión...”. (Verón, 2013)

Con algunas similitudes, la propuesta betesoniana, responde a una concepción sistémica de la comunicación que considera una lógica "circular", y donde la comunicación se ejecuta desde distintos niveles, tanto semánticos como pragmáticos; lo que significa pensar a la comunicación más allá de los actos verbales y del habla, e incorporar los elementos relacionales y de contexto. Los paradigmas direccionales, como sabemos, 
ven también a la comunicación como algo dado, eventos temporalmente ordenados con un comienzo y fin. Allí habría control del proceso y allí también la posibilidad de una comunicación efectiva, portadora de eficacia. Sin embargo, para el interaccionalismo comunicacional, lo que refiere, es una nueva conceptualización del comportamiento humano, cuyo signo específico sería plantear la importancia de una pragmática de la comunicación, de naturaleza sistema y circular. Este enfoque -evaluado también como un aporte a las ciencias que tienen interés en los fenómenos del conocimiento-, es posible concebirlo como una provocación que levanta el axioma de la imposibilidad de conocer desde la realidad; sino y más bien, el observador es capaz de ver lo que ve, lo que hace del fenómeno del observador un acto de observar, que no tiene sentido, sino es comunicado como aquello desde donde se observa, es decir, la metacomunicación. En síntesis, toda comunicación produce realidad, y en este sentido, la comunicación es una producción social y deja de ser un objeto natural para cumplir una función en el nivel de lo simbólico, devenido en información o patrón percibido y significado. La primeridad, si emparentamos la tesis de Verón a la de los sistémicos del interaccionalismo, sería la experiencia y las diferencias percibidas a partir de las cuales construimos nuestros supuesto, ideas e imágenes del mundo externo. Sería por ello, la mente el lugar en que se constituye la realidad o territorio de lo real. Con esos presupuestos, estamos -con la Escuela de Palo Alto y Gregory 
Bateson- en unas de las críticas más fundamentales a la afirmación sobre la realidad objetiva, lo que implica pensar a la comunicación humana, como factor del conocer. Para Bateson, la naturaleza sistémica de la comunicación se relaciona con la propia definición de "sistema", comprendida como un conjunto de objetos así como de vinculaciones y contactos entre los objetos, sus atributos, y donde los atributos -para el caso del sistema comunicativo- son sus comportamientos comunicacionales, el sin fin de relaciones que se producen, mantienen unido el sistema. La importancia de la dinámica de "intercambio" para el funcionamiento del sistema, es vital: "porque el sentido no es una cualidad del comportamiento considerado en sí mismo, sino que está dado por las respuestas de los otros actores presentes". (Verón, 2013: 52)

Aquí ya aparece el tópico de la circularidad, y se abre la pregunta: ¿dónde comienza la comunicación? lo que anticipa su propia descripción como paradigma, para superar todo atisbo de funcionalismo, aunque sin dejar de comprometer a cabalidad algunas entradas nuevamente del tipo "metafísica". Si dejamos de precisar que la realidad es pura construcción, entraríamos a una negación filosófica de la mundanidad del sujeto, y de esta manera, su propia cualidad histórica viene a ser obviada, en el sentido de su relación productiva con y en el medio, es decir, su materialidad devenida en cultura. Verón, al respecto, desliza allí una crítica del tipo epistemológica: 
Bateson ve en la mente un carácter "inmaterial de los procesos mentales". Aquí estamos en presencia de lo "inmanente", que es interno a un ser, o a un conjunto de seres y no es resultado de una acción exterior a ellos, por ejemplo, "la maldad es inmanente al ser humano": "Los procesos de intercambios entre individuos son ‘inmanentes'a los fenómenos observados". (Ibídem: 59)

A partir de lo anterior, nos atrevemos a situar una distancia epistemológica con los sistémicos: de alguna manera, el biologismo de los estudios de la mente frente a una antropología del contexto, puede ser una camisa de fuerza si queremos comprender la relación compleja y dinámica, entre la especie humana y el medio. Quisiéramos entender siguiendo a Verón- que los sistemas de audienciación contemporáneos deben observarse desde la compleja relación entre lo biopsicosocial. En esa dirección, Verón busca construir un esquema que podemos denominar nosotros como fundamentación de los montajes en el devenir de la historia de la mediatización. Estos esquemas son de especificidad sociosemióticos, es decir, operan los hechos como conciencia de realidad posibles de ser captados cognitivamente en el entramado de los estados mentales ya descritos en esta tesis. Particularmente, el sistema sociosemiótico como base para 
Revista de la Academia/ISSN 0719-6318

comprender la tesis del sistema de audienciación en reconocimiento, que se sitúa -si seguimos el argumento planteado líneas antes-, en la "terceridad del conocimiento", por la consideración que "todos los estados mentales son procesos de signo, procesos semióticos, pero no todas las cosas son pensadas como signo". (Verón, 2013:.33); y es en este razonamiento que, sentimiento - reacción - y pensamiento $^{3}$, corresponden a las tres dimensiones básicas de toda actividad cognitiva del homo sapiens y allí se ubica la raíz productora y productiva de la especie humana.

Extendámonos un poco más a partir del pensamiento de Verón. Éste ingresa a su propia concepción sistémica generando un esquema donde se representa un sistema social y un sistema psíquico; ambos territorios tienen a la base distintas filosofías; por un lado, tributa a Luhmann y por otro, cierta cercanía con Bateson; y por cierto, una crítica a la linguística como explicación de los fenómenos de la comunicación en tanto puro acto de habla, en desmedro de un homo sapiens que llega a su condición no como sujeto hablante individual, sino como lo que podría constituir una teoría de la subjetividad históricamente reconocible: "Porque está claro que, como resultado de la mediatización, los fenómenos de la conversación cara a cara entre personas constituyen apenas un fragmento mínimo de la semiosis social

\footnotetext{
${ }^{3}$ También lo hemos enunciado en el transcurso de este artículo como primeridad, secundaridad y terceridad, siguiendo a Verón, el que -no está demás decir- se ha inspirado en la Triada Pierciana.
} 
de la especie”. (Ibídem:.75). Aquí ya estamos “... en un modelo circular de feedback permanente entre ofertas y demandas". (Ibídem:.103) Porque es conveniente reconocer que las tecnologías abren nuevas posibilidades de manera sistemática, constantes, donde su último ejemplo, es la semiosis 2.0 (Verón se refiere así a la Web). Dicho lo anterior, ya tenemos las bases que nos permite poder analizar este nuevo sistema de audienciación, partiendo por la complejidad del mismo, donde sus condiciones de posibilidad técnica hacen realizable este nuevo eslabón en la historia de las audiencias, así como de la cultura que materializa esas condiciones, en el sentido que la propia historia de la mediatización ha creado esas condiciones; en esta perspectiva, sólo considerar el devenir último dado por los modernos medios de comunicación en tanto extensión de las primeras formas de mediatización que el ser humano ha conocido: la "Red" es un dispositivo mundial, es decir, un sistema que se caracteriza en lo específico por "su alcance" y por su magnitud, es decir unos progresos cuantitativos y cualitativos . Su potencia aún es inimaginable, por de pronto, las lógicas de consumo determinarán hasta dónde puede llegar su potencia virtual, esto es, con sólo observar el impacto económico de la convergencia de los medios a Internet, el inimaginable su impacto.

Este nuevo sistema de audienciación (estar-siendo-activo, en la comunicación) “comporta una mutación en las condiciones 
de acceso de los actores individuales a la discursividad mediática, produciendo transformaciones inéditas en las condiciones de circulación". (Ibídem: 281) Es decir, el sistema se apropia de las formas discursivas, de los habitus de montaje, y los amplía sin reserva. Las nuevas lógicas de la comunicación, exigen y ordenan, estar atentos al otro polo las gramáticas del reconocimiento-, anteriormente invisibilizado y consumido por la acción empoderada del emisor, lo que ahora permite perspectivar un proceso conducente hacia la obsolescencia de las antiguas formas dadas por los viejos medios, donde sus técnicas de montajes, no logran la velocidad de respuesta y de presencia en relación a las formas de reconocimiento contemporáneas. Por ello, en el nuevo sistema de audienciación, "los procesos de la circulación son el nuevo campo de batalla y esa guerra apenas comienza". (Ibídem: 282). Los usos y apropiaciones de parte del comunicante, de las nuevas condiciones en que se realiza la producción de sentido, corresponde a la batalla por dar, y vasta con observar la crisis de legitimidad, por ejemplo del periodismo, particularmente su versión televisiva, para ver el abismo entre la lógica del montaje de la producción audiovidual respecto del interpretante y los dominios que maneja éste y expresa a través de las lógicas de reconocimiento. Por ello, se hace necesario observar estos nudos, base de consecuencias, que esta nueva fase de la mediatización trae a este tipo de sociedades hipermediatizadas; porque no sólo se carece actualmente de 
un punto de despeje, sino precisamente, porque aún es un campo en disputa, que corresponde, como también históricamente ha correspondido, a la hegemonía de los discursos y quienes los producen. ¿Qué sentidos son los que se producen en la actualidad? ¿Cómo chocan con los que han constituido la vida moderna? ¿Qué pasará con la elite de los medios, productora de un verosímil en descomposición? ¿Y que hay de las elites del poder, las políticas? Son preguntas como enuncia el periodismo precisamente, en desarrollo, en tanto las respuestas las vamos construyendo en el día a día.

Ese es el escenario donde actualmente se produce la subjetivación y la subjetividad del comunicante. ¿Qué es lo que está a la base de esa relación? Lo que está a la base de esa relación es el inter sistema. No es posible pensar sistemas cerrados: históricamente el ser humano ha demostrado que su propio devenir ha sido la interrelación sistémica con su "ser ahí”, ahora también en el presente epocal del territorio virtual, como su "ser fuera de ahí". Volvamos a Verón:

"Intentemos una síntesis filogenética. Los fenómenos mediáticos, ¿son una precondición de los sistemas psíquicos de los sapiens? La respuesta es no.

Inversamente, los sistemas psíquicos, ¿son una precondición de los fenómenos mediáticos? La respuesta es sí. Los sistemas psíquicos, ¿son una precondición de los sistemas sociales? La respuesta es sí, pero no de una manera lineal, directa, sino a través de la emergencia de los fenómenos mediáticos. Entonces, los fenómenos 
mediáticos ¿son una precondición de los sistemas sociales? La respuesta es sí". (Verón, 2013: 301302)

Vayamos concluyendo: Verón apuesta a una historia de la semiosis, como transformaciones generadas por la tecnología que, reconfiguran permanentemente las relaciones de circulación, particularmente los "desfases entre producción y reconocimiento" y que se manifiestan como "cambios en las relaciones sociales". Desde esta perspectiva, Internet sería algo así como "un sistema social autónomo”, (Ibídem: 292298) una nueva materialidad, propia de la creación por los saberes asociados a la investigación de los sistemas autoreferidos y autoorganizados: “...esa materialidad no es otra que la producida por la exteriorización de los procesos cognitivos que hemos llamado fenómenos mediáticos que se inician con la fabricación de los primeros útiles de piedra”. Precisamente -escuchado lo anterior- estamos ya comprendiendo el inicio de la historia de la mediatización, que corresponde a un momento de cierta maduración de la invención que, parecía efímera al pasar de los días de millones de años, y que en un momento dado de esta historia, logra una presencia continua, reconocible tanto por su productividad como por la posibilidad posterior de ser transformada, lo que Verón a denominado la "persistencia y autonomía de los signos" como "...cualidades materiales resultantes de ese exteriorización”. (Ibídem: .299) En este sentido entonces, de naturaleza multi o inter sistémica, la producción social de la 
comunicación es lo que hace al sistema social, o mejor dicho, lo que hace vivir en sociedad.

La realidad de las transformaciones, en base a la Comunicación Mediada por Computador (CMC), corresponde a una nueva cultura que se está instalando. Toda cultura demanda el desarrollo de competencias nuevas que son gracias a dominios que le han precedido, es decir, esas "cadenas operatorias" devenidas en "disposiciones y/o habitus" (Leroi-Gourhan, 1971; Bourdieu, 2006). Mirado así, lo que vivimos en la actualidad con Internet como "artefacto cultural" (Hine, 2004), sería entonces el soporte técnico del desarrollo de una nueva cultura, una vez más la humanidad asociada en su reconocimiento al desarrollo de tecnologías; el desarrollo de la imprenta como medio mecánico y después el desarrollo de unos medios eléctricos masivos que, de igual manera, hicieron emergen una nueva cultura, la cultura de masas. Bajo estas lógicas, los actuales medios electrónicos digitales, asociados al desarrollo informático e informacional, instalan nuevas necesidades de aprendizajes y prácticas en la sociedad. Así, tiene sentido el que le llamemos "sociedad de la información y las comunicaciones" aunque este último término, si somos conscientes de lo dicho, estaría "demás". Bajo este sistema estaríamos en presencia de lo que Hine expresa como "formación de una comunidad de prácticas de conocimientos, lenguajes y bienes compartidos". (Ibídem: 319) Estos dominios -formación y desarrollo de nuevas 
Revista de la Academia/ISSN 0719-6318

disposiciones-, están a la base de estas transformaciones culturales. El punto crítico está en sí estamos ante la emergencia de una nueva cultura o corresponde más bien a las trayectorias de una qué no cesa en transformarse. Todos los "artefactos culturales" a lo largo de la historia del homo sapiens han transformado el entorno externo y su propia estructura interna: así también las relaciones inter sistemas, entre el sistema psíquico, los fenómenos mediáticos y los sistemas sociales (plural justamente porque han ido transformándose). Así vista las cosas, la Internet, corresponde a las transformaciones ya escritas por la historia de la mediatización, en tanto lugar de materialización de la semiosis producto de la técnica, y que no es otra cosa que la exteriorización de las facultades cognitivas de la especie humana. Pero la novedad no está en lo que nos deja la síntesis anterior, la novedad está en que lo que hace posible la intersección de los sistemas, es el flujo, y su conocimiento como forma del conocer: la conciencia como flujo da lugar al comunicante en un "estar - siempre activo"; por lo que toda lógica de reconocimiento -si entendemos el reconocimiento como uno de los polos de los procesos de circulación de sentido-, corresponde a ese tipo de estructura y coincide con el flujo de la producción devenido en "fenómeno mediático", es decir, la posibilidad de estabilizar "los objetos temporales"4 que, sistemáticamente con la historia de la mediatización, se

\footnotetext{
${ }^{4}$ Stiegler trabaja latamente este concepto en su obra, ya citada.
} 
han ido alojando en la terceridad ${ }^{5}$, la que por cierto, no es más que las posibilidades que los dispositivos de retención terciarias, permiten desde que el ser humano caído, ha hecho del pensamiento. Porque estos objetos temporales y su constante relativa autonomización y persistencia en el tiempo, se van estabilizando en la medida de la consolidación de los modernos medios análogos y posteriormente, los nuevos sistemas de comunicación digital, particularmente, una línea histórica posible de seguir desde la partida del fonógrafo, y el advenimiento de la fotografía, el cine y la televisión. A continuación, desnudaremos estas formas productoras, las de los sensorium, las partes que operan en los procesos de producción de sentido y lo que hace posible, las formas de reconocimiento en la era digital.

Las lógicas de reconocimiento como fuente de desarrollo del contrato/vínculo en la comunicación social

En este subcapítulo, desarrollaremos la tesis respecto de la existencia de un nuevo sistema de audienciación, como forma de comprensión de los procesos socio comunicativos contemporáneos. Las personas están encaminadas al despliegue de unas disposiciones, desarrollos de habitus, que permiten acceder al complejo mundo de la comunicación como principio de realidades, dispositivo que no es si no la expresión del desarrollo de la historia de los medios como exteriorización de las capacidades cognitiva del género 
humano, una capacidad que opera como flujo y hace posible la producción de sentido. Quizá, lo que está definiendo el cambio en nuestras vidas en asombro y perplejidad, no es si no otra cosa que los "procesos de individuación", como una trama de lo colectivo, que hoy pone en cuestión la idea de los procesos de personalización e individualización como ética a la base de nuestras transformaciones.

La posibilidad de comunicar y por ello de construcción de realidad en el género humano, es posible verificarse al establecer la existencia de distintos planos de ésta, particularmente -ya lo hemos planteado en el curso de la tesis, la dimensión de la realidad como "fenómeno mediático"; desde el hecho simple del intercambio cara a cara, a las posibilidades que el complejo mundo de las redes virtuales permiten en la actualidad, que no serían más que -desde una perspectiva interdisciplinaria- las posibilidades de montajes históricamente efectuados, cuya actualidad podría ser denominado como un "superlenguaje", propio del desarrollo histórico de la mediatización.

Volvamos a Stiegler. En el primer tomo de "La técnica y el tiempo" propone la problemática del determinismo tecnológico, prevé la evolución tecnológica como un "determinismo blanco" respecto de una "determinismo estricto": "Todo sucede como si la invención técnica cumpliera en forma aleatoria, pero certera, el cumplimiento de una ‘intención` técnica o tecno-lógica”. (Stiegler, 1994, 
p.60) Existirían unas invenciones como "operaciones de montaje", y no se trataría de "un linaje único", sino una serie de líneas técnicas. Al parecer, según los estudios antro y paleontológicos, distintos niveles intervienen en la invención técnica por encima de linaje tecnológico propiamente dicho, por de pronto, el conocimiento primario, secundario y luego, ya sabemos, el científico, así como las solidaridades con los otros sistemas y las coacciones e interacciones externas, por ejemplo, la situación económica, la voluntades políticas y los juego de poder en general, coacciones impuestas por la interdependencia entre los sistemas y los subsistemas, es decir, unas ciertas condiciones de posibilidad también en la producción del conocimiento, las invenciones propiamente, y el sentido que toman estos "hechos técnicos" en la vida de las personas. Aquí ya estamos en la cuestión de lo particular y lo general de las tendencias técnicas, donde la "lógica de la invención no es la del inventor. Hay que hablar entonces, de una tecnológica, de una lógica que anima propiamente la técnica misma"; al respecto, Stiegler sigue el pensamiento de Bertrand Gilles, que considera habría un ordenamiento propio de las técnicas, es decir, una racionalidad tecnológica; argumentos que chocan con la reflexión de Leroi-Gourhan, "para quien existe una tendencia técnica universal, en gran parte independiente de las localidades culturales en las que se concretiza el "hecho técnico", y que justamente, pueden entrar en conflicto con las culturas locales que la desempeñan porque aquel es universal mientras que éstas son particulares". 
(Stiegler, 1994, p.61) Es decir, un desarrollo técnico autónomo de las localidades culturales, lo que plantea "una articulación entre sistema técnico y otros sistemas", por cierto, el sistema psíquico, o lo que pudiera representarse como la toma de sentido y apropiación del hecho técnico. En esa dirección es que pensamos que no hay determinismo tecnológico, sino hay uso y apropiación del hecho técnico, de la que se nutren las tendencias tecnológicas planetarias, y que no es otra cosa que en el enfoque de Leroi-Gourhan, lo étnico "como factor de difracción diversificante ${ }^{6}$ del que sin embargo se nutre la tendencia universal”. (Ibídem)

A esa tendencia universal dada por una especie creadora, que se mueve en la inventiva, que circula precisamente por los espacios concretos de las prácticas, donde esas maneras de hacer toman sentido y otorgan plena pertinencia a la cosa creada que acude al mundo de relaciones, y allí se potencia; en ese enfoque también, las diferentes apropiaciones socioculturales que adquieren esas técnicas y objetos, lo que García Canclini a denominado la resignificación de los usos (García Canclini, 1993), las que por cierto intervienen fuertemente en los procesos de consumo como forma de

${ }^{6}$ Interpretamos con este concepto que la producción se diversifica y amplía, en ningún caso corresponde ya a algo "original, más bien, como se denomina por algunos autores e investigadores de la tecnociencia, corresponden a procesos de creación de diferencias. La formación de las sociedades tribales, por ejemplo, se mueven en este ampliar, que constituye finalmente, también la heterogénea historia de las etnias y formaciones locales. 
reconocimiento, lo que nos permite (como enfoque precisamente) instalarnos hacia la hipótesis respecto de la existencia del campo del reconocimiento como una manera de comprensión de los procesos de audienciación en la interrelación de los sistemas en juego, en las sociedades actuales: "Tanto en las ciencias como en las artes el concepto de campo acabó con la noción romántica e individualista del genio que descubre conocimientos imprevistos o crea obras excepcionales". (García Canclini, 2010: 32) Aclaramos lo anterior, para no reducir la cosa a lo meramente social (en su sentido débil), o a la pura cultura (como un alma, por ejemplo), que enmascaran un determinismos sociológicos o antropológicos, sino más bien, querer dar cuenta de la gama de relaciones en las que interactúan los que intervienen en los procesos de creación, producción y circulación, de las sociedades complejas que vivimos en la actualidad. Nuevamente, García Canclini interviene aquí para ayudar a la toma de posición, en el sentido de despejar toda adscripción a determinismos que dicotomizan el mundo de las relaciones humanas y su entorno, a saber:

“Al prestar atención a los desplazamientos de función y significado de los objetos en el tránsito de una cultura a otra, llegamos a la necesidad de contar con una definición sociosemiótica de la cultura, que abarca el proceso de producción, circulación y consumo de significaciones en la vida social. Conforman esta perspectiva varias tendencias, 
Revista de la Academia/ISSN 0719-6318

varios modos de definir o subrayar aspectos particulares de la función social y del sentido que la cultura adquiere dentro de la sociedad". (García Canclini, 2006:.35)

Esta suerte de introducción al mundo del reconocimiento, es del todo conveniente y necesaria. Uno de los sistemas que intervienen en la relación técnica/cultura es el político, es decir, el entramado discursivo de un poder que siempre busca hegemonizar el campo de las representaciones e imaginarios, en un tiempo dado. Y como la discusión respecto de los medios, las tecnologías y sus enfoques, han devenido en unos modelos que sistemáticamente fueron enajenando las techné de los sujetos, es que conviene explicar el asunto de la relación “invención/innovación” que propone Stiegler.

Intentemos retomar algunos tópicos anteriores de la mano de Stiegler: ¿Quién inventa qué? ¿Qué sería lo inventado? Es importante precisar que la relación (el campo) que une el "quién" con el "qué" es la "invención". Para el filósofo aparentemente "quién" y "qué" serían hombre y técnica. Para no pecar de ingenuos, detengámonos que dice de la técnica: "La tecnología se define en primer lugar como el discurso sobre la técnica. Pero, ¿qué quiere decir técnica? En general, la técnica designa hoy en la vida humana el dominio restringido y especificado de los útiles, los instrumentos, cuando no sólo de las máquinas...”. (Stiegler, 1994: 145) Reafirmado por Stiegler, 
en seguida, la techné implica un saber-hacer, aúnque hay algunas acciones que van más allá de un modo de comportamiento disposicional (por ejemplo, dice Stiegler, ser cortés, elegante, etc) sino que hay otros movimientos que se relacionan con "una producción, con una transformación de materiales, de 'materia prima' ...como por ejemplo, la cocina. En ese sentido, la técnica relaciona cognición y transformación material de la cosa, digamos de un qué operado por un quién, donde ambos, no son pertinente sin el uno. Lo que ha ocurrido con el pasar del siglo XX $\mathrm{y}$ publicitado fuertemente en el actual, son "las transformaciones del sistema técnico" (como autónomo) lo que ha traído sistemáticas consecuencias a los otros sistemas; allí residiría la diferencia entre "invención e innovación”, donde la innovación sería una economía de la socialización, es decir, una socialización que pretende la plusvalía como condición de desarrollo y el lucro como beneficio corporativo: por ello "la innovación es principalmente de orden económico". (Stiegler, 1994: 61) Podríamos anticipar entonces, que "la innovación" contrae obsolescencia, bajo la dinámica del eterno reemplazo como estrategia de las economías globales, particularmente bajo la ideología neoliberal. Y como la cosa se topa con las condiciones históricas de desarrollo del conocimiento, es decir, de la invención, este conocimiento tiende a entenderse (como una suerte de enfoque), en uno de tipo instrumental; allí ya hay una primera pérdida de reconocimiento, en tanto todo 
conocimiento, es enajenado del campo de relaciones propio de la invención, y también enajenado en el sentido de usurpado de los colectivos y comunidades que han llevado a cabo las inventivas. Es decir, la innovación estaría en un proceso sin fin, sin cesar, como siempre ha sido y así lo plantean las transformaciones históricas de las techné, sólo que ahora, parecieran estar por encima de "las condiciones técnicas, económicas y sociales"; una suerte de metafísica de la innovación, cuando lo "que suscita la invención es el deseo de innovación". (Ibídem: 68) Allí está la escapada de la técnica, que como efecto social pareciera ser algo autónomo al hecho creado, produciéndose un signo problemático entorno al reconocimiento que se vincula con los desajustes de la técnica con los otros sistemas, o con aquellos que Stiegler considera como "cultura". (Ibídem: 69) Por ello -y lo subrayamos-, para Stiegler es necesario hacer que nazca una nueva comprensión de la relación del ser humano con la técnica, ya que lo que está puesto en juego hoy "es la organización del porvenir, esto es, el tiempo". (Ibídem: 69) Allí, una suerte de mediador.

Lo cierto es que la "tendencia técnica" se concretiza en el "hecho técnico" la techné toma sentido en la comunidad humana, pero precisamente por su universalidad. Allí radica un punto de quiebre a propósito del ánimo global de los globalmen, que suponen que, la localidad del sentido, estaría 
en fuga; y lo que precisamente no está en fuga -si no coaccionado por las fuerzas que niegan lo común de lo otroes el reconocimiento: la tesis consiste entonces (a propósito de la (re) instalación sistemática de un nuevo sistema de audienciación), en que el reconocimiento se fue históricamente privatizando, donde las mediaciones institucionales constituyeron cierta autonomía, tanto como las mediaciones tecnológicas, fueron fundando cierto determinismo. Esta tesis quiere explicarse de la siguiente manera: los desfases entre los polos del reconocimiento fueron acrecentándose al extremo que éstos tuvieron que tener una intervención desde sus representaciones científicas. Una técnica moderna que no lograba, en un primer momento, reponer el principio de su propio invento, esto es, contribuir a las transformaciones humanas necesaria para las posibilidades de adaptación y anticipación (y viceversa) con el ecosistema y por cierto, con su sistema psíquico; lo que para Verón sería "la historia de la semiosis desde el punto de vista de las consecuencias de las transformaciones generadas por los soportes técnicos (donde) resulta claro que cada uno de los inventos de esa historia puede ser visto como una reconfiguración del desfase entre producción y reconocimiento...". (Verón, 2013: 292) Es decir, un proceso paulatino donde la comunicación ha jugado a la pérdida de sentido, o si se quiere, a la configuraciones de sólo algunos sentidos.Pero, ¿de qué hablamos cuando queremos precisar la cuestión del reconocimiento? Lo primero es que allí, en el 
discurso del reconocimiento, estamos ya en una teoría discursiva. Verón - lo hemos señalado más arriba-, busca como estrategia epistemológica de poner en crisis la lingüística para poder instalar un enfoque donde los actores de la comunicación se relacionan, para de este modo, producir precisamente los sentidos de toda acción discursiva. En específico, con el concepto de "reconocimiento" estamos al interior de una episteme que tiene como antecedente fundador la lingüística binaria saussuriana, cuya conciencia crítica (su crítica) permite pasar de allí al análisis de las formas "ternarias", si por ellas entendemos el análisis de toda escritura, y ésta como relato, narración o, si queremos llegar al ahora ya, como montaje. Porque, lo que nos interesa del polo del reconocimiento, no es un tipo de circulación improductiva, como la del tipo unidireccional, sino y por el contrario, observar la relación (inter) que posibilita "la apertura de ese espacio de identificación" resultante de una compleja convivencia entre "producción y reconocimiento". (Verón, 1993, p.74) La lectura (la escucha) de un texto, o de cualquier forma de producción de sentido, corresponde a "los desajustes entre producción y reconocimiento"; algo como, un tiempo de espera, pausa que le agrega sentido y que jamás mengua. Siguiendo el enfoque de Verón conviene volver a citarlo para confirmar la orientación de enfoque: "El reconocimiento en tanto efecto de apertura del espacio de identificación" (Ibídem) donde lo importante de considerar es 
respecto del carácter de "la lengua", comprendida ésta como un fenómeno que no es natural sino social, es decir, sacarle todo el positivismo e incorporar a todas las formas de la comunicación, su pertinencia en tanto fenómeno social y mediático; y por otro lado, como fenómeno psíquico, donde "el signo se convierte en la expresión de la autonomía del lenguaje en relación con la naturaleza en tanto universo referencial”. (Ibídem: 75)

"La materialidad del sentido y la construcción de lo real en la red de la semiosis" (Ibídem:.12) aparece en forma de "conglomerados de material significante" (Ibídem, p.124) siendo por ello posible de remitir a un "sistema productivo". Es por ello que requerimos insistir en la relación productiva en reconocimiento, que viene a fundar lo que Verón ha llamado la Teoría de los Discursos. En esos marcos conceptuales toma vida la tesis de una sociosemiótica o "semiosis social", la que entenderemos como "la dimensión significante de los fenómenos sociales", es decir, el estudio de lo que también podemos llamar los fenómenos mediáticos "en tanto procesos de producción de sentido", cuya base de comprensión tiene asiento en que "toda producción de sentido es necesariamente social" y no es posible explicar la vida humana, su evolución y transformaciones, sin explicar "sus condiciones sociales productivas", (Ibídem: 125) así como todo fenómeno social (y/o mediático en su sentido inclusivo) constitutivamente, corresponde a un proceso de producción de 
sentido. Porque, todo proceso en reconocimiento no puede nunca clausurar el sentido, sino por el contrario, lo abre siempre, lo extiende, lo que viene a plantear, si así nos lo permitimos, unas formas de creación fluidas, que se mueven entre "operaciones discursivas", “discursos" y "representaciones" (Ibídem: 131) que circulan y circulan; de ahí la idea de que la semiosis es también infinita.

En este proceso de circulación (de flujos) habitan los dos polos: el de la producción y el del reconocimiento, y fundan "el sistema productivo de sentido". Pero es importante señalar que el del reconocimiento habita fantasmalmente en la producción. La producción, en tanto flujo de imaginación, necesita previamente sentir el sentido. Allí la importancia del proceso de circulación como flujo, en tanto este enfoque requiere tener presente que, si se analiza un producto (cultural) es conveniente siempre que "apuntemos" a los procesos, por lo que conviene no olvidar que lo productivo no se haya en un esquema unidireccional, sino en toda la extensión de interrelaciones, pues en esas fricciones se produce la circulación del sentido, es allí donde quedan las "marcas" que siempre son de reconocimiento, porque "Para que algo sea considerado como condición de producción de un discurso o de un tipo de discurso, es necesario que haya dejado huella en el 
discurso". (Verón, 2004: 41). Realizada esta aclaración del reconocimiento como lugar de producción de sentido, que le da vida, existencia y razón al comunicante, es necesario aclarar el tema de los flujos.

Los flujos, circulan y contienen nuestra cognición. Son del origen y porque su origen tiene la precariedad del comienzo, es que se pueden representar (los flujos) en cadenas de repeticiones que se alimentan de la necesidad ortética de poner aquello que falta. Y aquello en falta (la carencia), procura la inventiva, supera la falta, hacen posible las transformaciones, mutaciones que tienen por base, la relación entre inconsciente y consciente -por decirlo de un modo-, a partir de una experiencia vital compleja, donde el darse cuenta corresponde a un hacerse cargo de la carencia devenido en una "acción inter-psicológica o inter-mental", que explicaría lo que Tarde describe como "la imitación, la invención y la oposición". (Tarde, 2011) Estas operaciones hacen lo social, toda vez que la especie ha creado como condición epifilogenética de existencia, a un "individuo psíquico" (Simondon, 2009) precedido por una individuación física, y de ésta a la individuación psíquica, fuente de toda transindividualidad (sujeto/objeto), la plegaria a la técnica, que tiene en el reconocimiento la forma de no quedarse en su soliloquio abismal. Precisamente en reconocimiento, lo social ha sido encarnado. Encarnado, en tanto posee las condiciones bioconstitutivas, donde el saber de ese individuo, es saber 
Revista de la Academia/ISSN 0719-6318

Hacia un mapa de la audienciación

colectivo posible de ser entendido como lo socialmente constitutivo. O si se quiere, no habría otra posibilidad de saber sino no es colectivo, desde la perspectiva que, toda producción de sentido, es social.

El ser humano, socialmente constituido, nos plantea entonces, que desde el origen del homo sapiens lleva consigo la carencia, y allí una falta fundamental que se anida, en la posibilidad de una memoria, lo que Stiegler denomina "la finitud retencional": ésta es "la condición de la conciencia en tanto que es siempre un flujo temporal". (Stiegler, 2001: 26) La propuesta profunda de Stiegler se sitúa en el problema de origen, nuestra condición de comienzo y su ineludible finitud del ser. Aquí se trata de poder comprender el concepto señalado anteriormente de "objeto temporal" o por decirlo más en común, los objetos percibidos que nacen ya con una "ausencia retencional", donde se nos plantea una paradoja, toda vez que la especie humano está constituido por unas maneras de lo "im-perceptible" que pueden definir la imposibilidad de una percepción total, por lo que siempre ese "objeto temporal" es modificado en el flujo de conciencia. Eso a lo que llamamos "realidad" y su posibilidad de comunicabilidad, no es sino apenas -como expresa

Stiegler- un "eco" como metáfora de "continuidad de lo que persiste”. (Stiegler, 1996: 335, 336, 337) 
Lo que persiste entonces nos abre unas condiciones de posibilidad para comprender la comunicabilidad, lo que permitiría abordar el problema a partir del tipo de conocimiento/saber que es posible contar como repertorio, abasto de ideas y representaciones de distintos niveles, siempre, bajo la condición epimeteía, es decir, problemática: "Cualquier conocimiento es sólo un re-conocimiento, una anamnesia. El saber es memoria". (Ibídem: 295) Aquí estamos situados en los límites propios de la conciencia y de su interpretación como tal, es decir, de su metaconocimiento; donde la cognición pensada como memoria siempre busca "suplir" esas limitaciones, es decir, somos una especie en búsqueda de un permanente suple; y esas limitaciones han operado como un dispositivo que genera unas motivaciones lúcidas, deseos y creencias, que han orientado el sentido de adaptabilidad, en tanto comportamiento necesario, pausa, en el flujo creativo. Serían estas las operaciones que están en la base de los procesos que permiten que los "objetos temporales" tengan persistencia y autonomía en el tiempo. Porque con la secundaridad es posible hacer consciente el instante primario, la lógica de superposición facilita que la primeridad no sea si no esa "consciencia secundaria", que, a lo ojos de Eliseo Verón, origina la idea y el momento, es decir, cuestión posible de ser interpretada como el establecimiento de las relaciones tiempo/espacio que a causa de una pausa, ha hecho que la estrategia ortética pudiera expandirse hasta los confines de la historia. Las prótesis, en cualquiera de sus 
Revista de la Academia/ISSN 0719-6318

formas, siempre plantea una función de "anticipación" a fin de un "programa" cuyo carácter se orienta siempre a la producción y reproducción de la cultura que la hace posible, relación compleja entre el "quién" y el "qué".

Con lo dicho anteriormente, estamos queriendo decir que, la realidad mundana, producida por una conciencia finita, en su existencia hacia la posibilidad de persistir, ha tenido que amalgamar primeridad y secundaridad; idea y momento; percepción y encuentro, bajo el propósito programático de constituir un presente retenido y significado. Es en este sentido que, el objeto temporal, requiere de una "trascendencia" y ésta es posible pensarla, en lo que es la capacidad interpretante de los individuos que afincan, insertan e inscriben, las imágenes como imagen de consciencia. Allí, precisamente, el papel de todas las escrituras, la prótesis para superar una memoria evanescente, en continuo retiro y fuga, en contradicción y superación de su falta; lo que al fin y al cabo le ha permitido al género humano, contar la historia, es decir, poder tener un presente pretérito, así como un presente programático, salida a los modos que constituyen toda semiosis social: “Toda impresión temporal está habitada de retención y toda retención, primaria o secundaria, depende de una impresión originaria". (Stiegler: 341) Por ello importa, a la hora de pensar el "quién", es decir, el comunicante, tener como fundamento fuerte la historia de las mediatizaciones, o de otro modo, el devenir de las 
estrategias humanas orientadas a lo ortético; pues ante la falla humana de la "pérdida de memoria", su universo interpretativo, socializado en el curso de la vida de los hombres y mujeres, es lo que ha permitido finalmente, su individuación, o su consciencia como especie que transciende y supera lo meramente individual. Porque históricamente aparece un qué que viene a suplir la falta; soportes, medios que fijan, registran y ocasionan, en este gesto adaptativo, acumulativo y anticipatorio, la autonomía respecto del tiempo de esos objetos temporales, y por ello, la facultad exteriorizada de poder construir una "consciencia de imagen", en tanto recuerdo terciario. Entonces el "qué", se puede comprender, siguiendo a Stiegler, como "soporte de recuerdo". En esta operación temporal, el primero y el segundo inmanente es completado por un tercero trascendente, a tal nivel, que el "objeto temporal" a tomado forma, a partir de las operaciones, por ejemplo, de captación de la imagen, el sonido, y luego, de imagen en movimiento: y todo ello corresponde al "qué". Y allí está su relación dialéctica, toda vez que la posibilidad de la pérdida de memoria es precisamente lo que constituye la memoria misma. (Stiegler: 341, 342, 343)

Con estos fundamentos, nos atrevemos a plantear algunas hipótesis prospectivas ${ }^{7}$ : el desvanecimiento de la

\footnotetext{
${ }^{7}$ Pensando en la ciencia "que se dedica al estudio de las causas técnicas, científicas, económicas y sociales que aceleran la evolución del mundo moderno, y la previsión de las situaciones que podrían derivarse de sus
} 
temporalidad vivida, se interrumpe a partir de la emergencia de un conjunto de operaciones que, sistemáticamente, se ha ido realizando desde el origen del Sapiens, como exteriorización de sus capacidades cognitivas, en tanto creación de cultura. En este devenir, sería "el recuerdo terciario" un guión, en tanto una consciencia de imagen, ya estabilizada, que ha tenido por efecto: “...la posibilidad de autonomizarse del flujo vital ordinario, del puro tiempo de la reacción y de la acción, del tiempo de los músculos y de los nervios dominados por el sistema reactivo vital...”. (Ibídem: 342-343)

A esta altura del recorrido discursivo de la tesis, se nos aparece el fundamento de aquello que explica la eficiencia de toda retención terciaria, inherente a toda actividad humana en la contemporaneidad, a saber: todo proceso de "retención de retenciones, es un procesos de selección”. (Ibídem: 345) En este sentido, todo recuerdo secundario es indisociable, no es posible oponerlo o desestimarlo del recuerdo primario, y es por ello que como fundamento, el enfoque nuestro, sustentado en el recorrido histórico socio-cultural de la especie, demuestra que el recuerdo terciario es también esa inmanencia de origen (no así una trascendencia), ahora, como "consciencia de imagen" denominada hoy "soporte", sean análogos o digitales, toda vez que su socialización (por más 
de tres siglos de continuidad y discontinuidad), radicaliza las formas perceptivas dando "la posibilidad de la experiencia de un objeto temporal", y es en esa perspectiva que la consciencia de imagen arraiga recíprocamente la primeridad y secundaridad. El acople de los tres estados mentales de la cognición. En ese orden, sería la capacidad de imaginar lo que está a la base del juego de seleccionar como procedimiento de construcción de una consciencia de imagen. En ese proceso de selección, el operador interpretante, le da vida; trae aquello ya ido, en un estar-siendo-activo, como si la sola presencia diera pertinencia a la realidad de ese real. Esta "selección" (tal como la selección de los innumerables fragmentos que constituye la agenda noticiosa y de la ficción que configura la realidad mediática del mundo) operaría en el nivel cognitivo, donde el modo de operar, se ha exteriorizado hacia una ortétesis de la imaginación: el mejor ejemplo está en el cine, luego la televisión y después -ahora- lo que llevamos de Internet como lugar donde el espacio y el tiempo, adquieren nuevos sentidos.

Nuestra continuidad temporal -en tanto seres conscientes- es siempre discontinua, y en ese sentido, bajo esa falla, los procedimientos de selección operarían fuertemente con el recurso de "la repetición", donde el objeto temporal ya no es idéntico $^{8}$, es decir el producto de la repetición no es exactamente eso que fue, sino la posibilidad de flujo de

\footnotetext{
${ }^{8}$ Difracción diversificada.
} 
consciencia como arte del montaje, donde hay un guión predispuesto, de un qué terciario "que es la ortesis" y que inevitablemente, ya es parte de esos flujos de consciencia; es decir, no es posible pensar la memoria, y la comunicabilidad de la vida (la experiencia) en tanto objetos temporales, sin el producto de la cultura y los sentidos que ella produce, situada en la realidad ya por algunos siglos mediatizada, como objetos temporales experienciados y estabilizados, burlando ese tiempo que alguna vez fue inexorable.

Es por ello que cuando hablamos del sujeto/ciudadano/individuo comunicante, estamos refiriéndonos a un ser consciente que desde el origen está inscrito en la historia de la mediatización. Las radicales transformaciones que la humanidad ha experimentado los últimos ochenta a cien años, plantean que transitamos por mutaciones con consecuencias de tipo cognitivas: no es sólo el saber y la información que tenemos de nosotros mismos, en cuanto a cómo funciona el "aparato cognitivo", sino que su misma exteriorización es la que corre los límites del pensar moderno. Hay una memoria mundial, y por ello, una comunicabilidad que sistemáticamente se ha ido deslocalizando, lo que plantea mutaciones culturales, referidas en esta tesis como tópico general. Estamos en presencia de un nuevo tipo de acontecimiento que abarca nuestra temporalidad cotidiana, y que hace pertinente, por ello, replantear las teorías que han explicado a la 
comunicación, los sistemas de comunicación social y particularmente lo que nos ocupa, los sistemas contemporáneos de audienciación.

"Que, en efecto, esta época sea la de las industrias de programas y de memoria industrializada tiene como consecuencia que el producto de la memoria industrial es un flujo en el que aparecen objetos temporales (cuyo carácter de flujo coincide con el flujo de las consciencias a las que afecta) de un tipo absolutamente singular". (Stiegler 1996: 369-370)

Es en este contexto epistemológico, en que se hace necesario pensar al comunicante y el sistema de audienciación que habita. Ese sistema, precisamente, es el de las formas y maneras contemporáneas que hacen a la memoria cultural, social e histórica. No es posible vernos de otro modo, en tanto la comunicabilidad es también histórica y puede ser pensada desde una historia de la mediatización. ¿Qué de lo que vivimos, ya mediáticamente, es vivido como experiencia inmediata? Allí, en esa pregunta, aparece como próximo un nuevo campo de alfabetización, que ni más ni menos, ha dificultado precisamente los antiguos campos de socialización humana respecto del mismo "quién" que ha ido creando un "otro quién", por un "qué" que por alguna razón "oscura" se ha querido autonomizar, en tanto estrategia de expansión de una economía que necesita generar y generar riqueza acosta del ecosistema, incluyéndonos a nosotros en éste. Allí, una ética y una episteme que buscar un rendimiento 
que tiende a enajenarnos del "qué", de su producción y reproducción. La pregunta entonces por el sentido y uso de las tecnologías, es una pregunta por la humanidad. En el contexto actual, de la segunda década del siglo XXI, los flujos de consciencia, mediados por los flujos de consciencia de imagen ortéticos, trastornan los modos humanos tradicionales hacia una disgregación; allí, las dificultades de pensar las subjetividades/intersubjetividades, la relación individuo/colectivo, que hacían posible los imaginarios que recorrieron la modernidad; donde al parecer, habría que mirar procesos que pueden dar respuesta -desde otras lógicas-, que complementen este enfoque, y que refieren a una teoría de los flujos, en el contexto de unos procesos de transindividuación (Simondón, 2009).

Dicho lo anterior, conviene como corolario de este capítulo, complejizar nuestra hipótesis con el fundamento que está a la base de lo ya comentado. La relación del flujo de conciencia como dinámica que perpetúa la vida social, su producción y reproducción; y los procesos de individuación, visto desde una perspectiva que quiere superar (como modo explicativo) el problema de las subjetividades/intersubjetividades pensando estos fenómenos como procesos de "transindividuación".

Acudamos entonces a Tarde. Este observa la sociedad en su devenir como "la organización de la imitatividad" (Tarde, 2011: 46), en tanto el cerebro, es un órgano repetidor de los 
centros sensitivos, compuesto de "elementos que se repiten unos a otros": "Así, todo acto perceptivo, en cuanto implica un acto de memoria -es decir, siempre- supone una especie de hábito, una imitación inconsciente de sí mismo por sí mismo". (Ibídem: 51.52) Caracteriza a estos "actos del cerebro" como "presocial o subsocial". En este sentido, podemos aventurar la existencia de una cercanía de Bourdieu con este punto de vista, considerando que Tarde considera el "hábito" (no habitus) como presocial, siendo éste "un movimiento en grupo de músculos". Si pensamos en la primeridad, éste estado mental, estaría anclado a un reducto existente antes de "la caída", pre darse cuenta y actuar; aunque Tarde, luego comprende lo perceptual como "idea", unida a su vínculo con lo social: "Esto no significa que la idea sea una acción abortada, como se ha pretendido: la acción no es otra cosa que la prosecución de la idea, una adquisición de fe estable. El músculo sólo trabaja para enriquecer el nervio y el cerebro". (Ibídem: 52)

Aquí observamos una separación entre idea y acción, entre músculo y aparato cognitivo, entre primeridad y secundaridad, entre precepto y momento, entre un sentir y un hacer. Ante la contradicción que interpretamos, parece luego el autor acudir al reparo:

"Pero si la idea o la imagen recordada ha sido originalmente depositada en la mente por una conversación o una lectura, si el acto habitual ha tenido por origen la visión o el conocimiento de 
una acción análoga de otro, esta memoria y este hábito son hechos sociales a la vez psicológicos; esta es la clase de imitación de que tanto he hablado más arriba. Es una memoria y un hábito, no individuales, sino colectivos". (Ibídem)

Así vista las cosas, el lazo social "se produciría de la siguiente forma: un modo de hacer, sentir o pensar surge en un individuo y se transmite a otro que lo repetirá sirviéndole de ejemplo a un tercero, que será copiado a su vez (...) Esto es lo que Tarde denomina "rayo", "flujo", o "corriente imitativa". Es en ese proceso que "lo diferente se vuelve semejante, y el primer paso para la conformación de identidades y conjuntos allí donde había una dispersión de elementos heterogéneos". (Tarde, 2011:17) ${ }^{9}$ Es en este sentido que Tarde piensa en el concepto de "flujo", razonado como "fluir-confluir y diferir"; es decir, posible de interpretarse como movimientos aleatorios que permiten construir, en esas oscilaciones, la sociedad y sus individuos. Esos flujos se producen y reproducen constantemente en pleno de la interacción social, imitándose e imitando, donde lo importante no es el acto de imitar "sino lo imitado". (Ibídem: 17-18) Esa imitación tiene un lugar, imitación devenida en "creencias y deseos"; y ese lugar para nosotros sería la invención. Para Tarde "toda invención tiene lugar en un individuo, por lo que el "innovador" constituye un espacio, también un momento; es decir, una secundaridad que, en la

${ }^{9}$ Corresponde al prólogo del libro denominado "Sociología molecular" escrito por Sergio Tonkonoff. 
medida que es imitado (el invento) la invención se constituye socialmente: un elemento del flujo que modifica lo anterior, y produce "espacios nuevos", si acaso es pertinente y cristaliza en esa idea primera. Sólo que ese individuo, paradojalmente, es por la experiencia comunitaria, local que ha tenido, donde los procesos de socialización, en sus distintos niveles, le otorgan su subjetividad referida siempre a una alteridad propia del contexto mundano que habita.

Nosotros hemos hablado de la exteriorización de la cognición humana, ésta como creatividad, y siguiendo a Tarde, como invención, posible de ser considerada como el punto cardinal que explicaría "el motor de la evolución social": y aclara el autor que, entiende el concepto "invención”, no como "única fuerza activa ", sino como "fuerza rectora, determinante, explicativa". (Tarde 2011: 69) Es decir, la inventiva sería apenas el detonante, el acelerador, de las transformaciones de la humanidad; la chispa que hace arder el trigal. Esa "iniciativa individual" (la invención) no es nada si esa sociedad, su ecosistema, las costumbres, ideas, hechos, hábito adquirido, no existieran pertinentemente. $\mathrm{O}$ sea, se configura allí una apelación a lo que hemos llamado modernamente como mecanismos o pautas de socialización. En ese sentido, siguiendo a Leroi-Gourhan, el genio, no pasa de ser sólo la construcción de un quehacer potenciador de la comunidad; y es allí exactamente, en el territorio, donde solamente son posibles las transformaciones; allí, en ese lugar donde el flujo 
corresponde a un movimiento entre lo heterogéneo y lo homogéneo: lo que sería una sociedad ya con memoria, aunque fallada y por eso mismo siempre inventada, es decir, un lugar donde el grupo comparte a través de la escritura, por mínima que fuere (primaria), la idea o invento encontrado, posible de compartir para que se le ponga sentido. Aquello que Tarde denomina "rayos imitativos". Pero hay que precisar que Tarde, aún está -desde nuestro enfoque- en el mundo de la linealidad, es decir, en flujos comprendidos desde un primer orden. Todo invento tendría elementos de lo antiguo que precede a lo nuevo; la continuidad/discontinuidad y ruptura, no aparece en su abecederario. Aún su enfoque tiene en su centro un binarismo, dualismo, propio del paradigma fundacional de la época. Sin embargo, no es menor el intento y rehuye, buscando otras argumentaciones para saber en qué consiste esta originalidad". (Tarde, 2011: 77) El desafió entonces es superar el elemento basal de la continuidad a secas respecto de lo anterior; para ello repara en dos cosas: 1) El estado mental característico del cerebro individual, es decir, un cerebro diferentemente adaptado a la función a cumplir; 2) una perspectiva del sistema social (lo exterior) percibida y acoplada a una secundaridad y terceridad, estados mentales propio de un interpretante (siguiendo a Verón): “...punto de vista (...) que ha escapado por un momento a la hipnosis social”. (Ibídem: 78) Allí, hay una confluencia, con lo que unas décadas después emergería desde el pensamiento de Adorno y Holkhaimer, comprendida como teoría de la 
alienación, en el sentido de un ser humano que se confronta a su realidad desde una acción crítica-reflexiva, esto es, como unas operaciones de comunicabilidad productora de sentido, acople de lo sensible, la mundanidad y su posibilidad programática.

Vale finalmente recordar que Tarde busca pensar una sociología distinta a la fundante, aunque no logra zafarse del todo: no por ello, sus definiciones no pudieran ayudar a la comprensión de la tesis que exponemos, aunque resulte contradictorio a estas trayectorias discursivas, pero en fin, el caso está en arriesgar a fin de poder establecer un mínimo comprensivo; por lo que ahora estamos ya en condiciones de arribar a los procesos de transindividuación, sin antes citar a modo de remate a Tarde:

"Es gracias a esa percepción de la naturaleza exterior desde un nuevo ángulo que el encuentro de dos rayos imitativos en el cerebro del sabio, del ingeniero, del artista, se vuelve fecundo, se transforma en invención. De hecho, gracias a ese contacto directo y genial con la naturaleza, dos ideas conocidas que hasta ese momento parecían no tener nada en común, aparecen como unidas una a la otra por una relación de principio a consecuencia, o de consecuencias diferentes de un mismo principio, o por una relación de medio a fin, o de medios diferentes de un mismo fin". (Ibídem:80)

Señalar necesariamente, para poder retomar el argumento que Stiegler busca instalar en su obra: una memoria epigenética, 
como marca de nuestra trayectoria social, cultural e histórica. Epigenética, interpretado como el conjunto de sucesos químicos (imaginamos los flujos de consciencia), de reacciones que modifican la actividad biológica (el ADN) pero sin modificar la secundaridad, es decir, la interacción de los genes con el ambiente. Esta huella epigenética, precisamente, no son genes; vale recordar que no sólo los genes influyen exclusivamente en la genética humana y/o en los organismos vivos. Por ejemplo, nuestra propia experiencia daría lugar a variaciones, cambios en el material genético. Por lo que se abre la cuestión, no sólo a la variable interna (la auto organización de las células) si no, también los factores externos (el ecosistema: luz, temperatura, humedad, radiación, etc), que entran a tallar en nuestras conformaciones.

Pero, el devenir de la creación humana, es la formación y desarrollo (continuo/discontinuo) de la cultura ortética, la que estaría interviniendo los desarrollos de la humanidad, radicalmente, al límite de efectuarse cambios societales que difícilmente logramos dar cuenta. La prótesis como creación humana, es parte del momento inicial, donde la cultura es el producto de esa interacción de origen, de tipo psicobiosocial. Con este fundamento, resituamos la perspectiva donde es posible interpretar la relación Qué/Quién, sin caer en la trampa de la pura y transparente auto organización del organismo, y podamos comprendernos como una "memoria epifilogenética", es decir, una memoria exteriorizada, cuya 
praxis experiencial hace las posibilidades de su propio dominio. Es decir, fruto de la creación humana que es a su "semejanza" social: la técnica es creada bajo ciertos términos y esa lógica basal, define la relación que el quién tiene con el qué; sin esa exteriorización -por causa de la carencia del homínido- no hay evolución transformadora (lejos de la perspectiva darwiana), en el sentido que las transformaciones del ser humano, se han sucedido, en interacción fundamental con su ecosistema. De este modo se puede precisar acerca de que, los procesos de individuación (sugeridos por Simondon) es a la constitución física, de un bípedo que avanza, y por ello una maduración biológica (nuestro cerebro, por ejemplo) hasta perfeccionarse psíquica y socialmente, este último estado como el corolario representado en la individuación colectiva. Para Simondon, ese camino abre la posibilidad a la creación que deviene en técnica. Es decir, una suerte de evolución que, difícilmente puede ser pensada como no lineal, y que no arriba a ser pensada con su defecto de origen. En ese sentido, ese mundo pasivo del receptor (que ya no tiene más espacio de ser pensado de ese modo) no permite reconocer un origen distinto al de un ser fecundo desde su caída, y propone, por el contrario, la imposibilidad del estado pasivo por una posición de emisor de origen, lo que nos permite introducir, la esperanzadora idea de Stiegler, de volver a ese momento de individuación colectiva (siguiendo a Simondon): allí, se superarían los procesos de personalización, en el sentido lipovetkiano, es decir, procesos orientado al individualismo 
narcisista, comprendido estos como un modo de enajenación o desviación radical del género humano, en la transición de una sociedad disciplinar a una de control. Habrían unas nuevas formas de socialización, donde los proyectos que animaron la sociedad los últimos decenios, comienzan a mostrar sus principios contradictorios.

La buena noticia está en que, precisamente, la creación devenida en nuevas tecnologías y éstas como exteriorización de la cognición humana, abriría una vez más las condiciones de posibilidad hacia el ejercicio en la experiencia de la inteligencia colectiva en la especie, de la que Lèvy nos ha hablado. Estamos pensando en la confrontación societal entre una ética individualista, cuyo límite es la ideología y praxis neoliberal y una nueva ética comunitaria orientada al comunismo no colectivista. Nueva en el sentido de su continuidad y cambio, fundada en un algo de origen, que interpretamos como de reconocimiento: el comunicante, viene a ser la mundanidad que supera el prototípico estado ético del individualismo, que viene incesante triunfando. La tesis epifilogénetica de Stiegler y la visión histórica sobre la sociedad mediatizada (es decir el qué como nuestra forma de habita) busca superar una epistemología ontogenética, en tanto procesos que modifican a los seres vivos desde la fecundación hasta la reproducción, de corte biologísta, para de esta manera, incorporar una interpretación desde un enfoque que observa los procesos en relación de las interacciones que 
se suceden entre sistema social y sistema psíquico; cuyos procesos, son de índole físicos, biológicos, psíquicos y sociocomunicacionales. Esto significa dejar a meridiana claridad que, estar en el lugar de lo colectivo corresponde a una relación del género humano, espacio/temporal, que requiere del complemento colaborativo con lo otro y los otros, que es también una forma de superación de las lógicas grupales, las que requieren el alineamiento a los liderazgos donde el individuo pierde su individuación, ya que el grupo es la voz del líder, sujeto que establece unas reglas a seguir, es decir, unas lógicas de reproducción en desmedro de la productividad colectiva. En el sentido gramcsiano, se puede precisar que se trataría de superar el sentido común como "sentido pedestre" por un "buen sentido" o sentido crítico-reflexivo.

Ahora, podemos ya definir lo fundamental de este comunicante: Este quién, logra hacer complementaria la relación comunicativa e histórica, entre transmisióncomunicación y objetos temporales. Este modo de acoplamiento se verifica en las diferencias que tenemos al percibir la relación en la experiencia del tiempo y el espacio. La virtualidad, condición de esta nueva cultura “ciber", supera (potencialmente) la autonomía del tiempo respecto del espacio, en el sentido de que la comunicabilidad (la producción social del sentido, la semiosis) está superando la necesidad de traslado; es decir, la experiencia donde el espacio se subordinaba al tiempo, cuyo paradigma histórico 
ha sido la modernidad entendida como sociedad disciplinaria. Al respecto, Tarde comenta acerca de una "sugestión a distancia" para así caracterizar una propiedad que haría posible una relación "en proximidad": "Los individuos que componen un mismo público, es preciso que hayan practicado mucho tiempo, por el hábito de la vida social intensa, de la vida urbana, la sugestión en proximidad”. En esa perspectiva, "la formación de un público supone, pues, una evolución mental y social mucho más avanzada que en formación de una multitud". (Tarde, 2011: 209-217) Precisamente, por eso, se trata de superar la concepción y concepto de "comunicación masiva”, acción homogénea dirigida hacia unas gentes indiferenciadas, soporte fundacional de las teorías de la comunicación, base de las epistemologías hipodérmicas y efectistas de la comunicación social de principios del siglo XX, hasta pasado las siete décadas del mismo. Tarde, ya a principio de ese siglo, desde su sociología apartada de una sociología de masas y de una psicología conductista, dijera otra cosa.

De este manera -a partir de estas trayectorias discursivashemos "caído" en el comunicante. Éste tiene aún un largo camino para volver a su ancestral posición: tuvo que pasar por ferias, peregrinaciones, aglomeraciones, "multitudes tormentosas" (Tarde, 2011); tuvo que hacer de la calle el teatro de las representaciones de su carácter y formas de comportamientos en tanto configuración de su ser público 
(Sennett, 2002); chocar y toparse en angostos bulevares y callejuelas en nacientes ciudades relatadas por los modernos rusos del siglo XIX y XX y que Marshall Berman compone como rompecabezas para hablar de la modernidad (Berman, 1998). Ciertamente, y es mejor no olvidar, que un qué, como lo ha sido la imprenta, tomó posición fundamental para cimentar esas formas modernas de volver "a ser", en tanto escritura de una memoria olvidadiza, que permite la programación y el ordenamiento prospectivo, hasta lo actual nombrado como "prosumidor" o "usuario", neologismos que incorpora la lengua contenida en el alfabeto neoliberal, que corre por nuestras venas. En esa medida y razón, el concepto comunicante, plantea la posibilidad de diferenciar sujetos en comunicabilidad, para de este modo estabilizar una cierta comprensión de esta dimensión fundamental del ser humano, en el contexto del nuevo y venidero sistema de audienciación planetario.

\section{Referencias bibliográficas}

Bateson G. (1971), Pasos hacia una ecología de mente, Buenos Aires, Editorial Lohlé-Lumen.

Bateson G. (1998), Espíritu y naturaleza. Buenos Aires Amorrortu.

Berlo D. (1984), El proceso de la comunicación, Buenos Aires, El Ateneo Editorial. 
Revista de la Academia/ISSN 0719-6318

Berman M. (1993), Todo lo solido se desvanece en el aire, México, Siglo XXI.

Bourdieu P. (2006), La distinción. Criterios y bases sociales del gusto. Madrid, Taurus.

(2006), La sociedad sin relato. Antropología y estética de la inminencia, Buenos Aires, Ekatz Editores.

(2006), Diferentes, desiguales y desconectados. Mapas de la interculturalidad. Barcelona, Gedisa.

(1993), Culturas Híbridas,. México, Grijalbo.

Giddens A. (2011), La constitución de la sociedad. Bases para la teoría de la estructuración. Buenos Aires, Amorrortu.

Hine C. (2004), Etnografía Virtual. México, Editorial UOC.

Leroi-Gourhan A. (2004), El gesto y la palabra, Caracas, Ediciones de la Biblioteca. Universidad Central.

López A., Parada A. Simonetti Franco (1995), Psicología de la comunicación, Santiago, Ediciones U.C.

Maturana H., Varela F. (1994), El árbol del conocimiento. Santiago, Editorial Universitaria.

Orozco G. (2011), “Audiencias. Mediaciones y televisión pública: la deconstrucción múltiple de la televisión en la era 
del avasallamiento mediático", en: Televisión pública: del consumidor al ciudadano, Omar Rincón (Compilador) VV.AA., Bogota, Convenio Andrés Bello.

Rodríguez D., Arnold M. (2011) Sociedad y teoría de sistemas, Santiago, Editorial Universitaria.

Sennett R. (2011), El declive del hombre público. Barcelona, Ediciones Península.

Simondon G. (2009), La individuación, Buenos Aires, Cactus.

Stiegler B. (2001), La técnica y el tiempo. El tiempo del cine y la cuestión del malestar, País Vasco, Cultura Libre.

Stiegler B. (1996), La técnica y el tiempo. La desorientación.Cultura Libre, San Sebastian, Ediciones Hiru Hondarribia.

(1994), La técnica y el tiempo. El pecado de Epimeteo. Cultura Libre, San Sebastian, Ediciones Hiru, Hondarribia...

Tarde G. (2011), Creencias, deseos, sociedades. Buenos Aires, Cactus.

Verón E. (2013), Semiosis Social, 2.0. Ideas, momentos, interpretantes. Buenos.Aires, Paidos. (2004), Fragmento de un tejido, Barcelona, Gedisa. 
Revista de la Academia/ISSN 0719-6318

(1996), Semiosis Social. Fragmentos de una teoría de la discursividad. España,.Gedisa..

Artículos en periódicos, revistas e internet

Orozco, Guillermo. La condición comunicacional contemporánea. Edición CIESPAL. Quito. 2011. (Pp. 377408)

Peirce Ch. (2003), Fundamento, objeto e interpretante. Traducción castellana de Mariluz Restrepo.en: http://www.unav.es/gep/FundamentoObjetoInterpretante.htm $\underline{1}$ (Entrada 15/12/2015 18.30)

Regillo R. (2002), "El otro antropológico. Poder y representación en una contemporaneidad sobresaltada", en Barcelona Revista Analisis № 29 (pp. 63-79).

Simondon, G. (2016) "La mentalidad técnica", en Revista Demarcaciones $\mathrm{N}^{\circ}$ 4. (pp.26-36).

Stiegler, B (2016), “Caída y elevación. La apolítica de Simondon" en: Revista Demarcaciones № 4 (pp.57-68).

Urteaga, E. (2010), "La teoría de sistemas de Niklas Luhmann", en Contraste. Revista Internacional de filosofía, vol.XV, pp 301-317. 